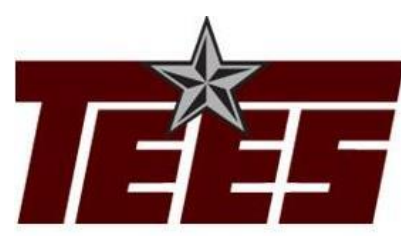

MARY KAY O'CONNOR PROCESS SAFETY CENTER

TEXAS A\&M ENGINEERING EXPERIMENT STATION

$19^{\text {th }}$ Annual International Symposium

October 25-27, 2016 • College Station, Texas

\title{
System Dynamical Simulation of Risk Perception for Enterprise Decision-Maker in Communication of Chemical Incident Risks
}

Mingguang Zhanga*, Xuedong Wang ${ }^{\mathrm{a}}$, M. Sam Mannan ${ }^{\mathrm{b}}$, Chengjiang Qian ${ }^{\mathrm{a}}$, Ji yang Wanga

ajiangsu Key Laboratory of Hazardous Chemicals Safety and Control, College of Safety Science and Engineering, Nanjing Tech University, Nanjing, 210009, China

bMary Kay O'Connor Process Safety Center, Artie McFerrin Department of Chemical

Engineering, Texas A\&M University System, College Station, Texas 77843-3122,USA

\begin{abstract}
Risk communication is an effective way to understand, assess and manage risk of chemical industrial parks, a process which requires the involvement of stakeholders. However, different risk perceptions may cause sorts of barriers formed in risk communication, sometimes resulting in mass confrontation incidents. Enterprise decision-makers play a key role in this process and further risk management. In this paper, a system dynamical model is established to interpret the feedback of this subjective process and analyze the mechanism of the barrier formation. To study the changes of risk perception of enterprise decision-maker in the face of incidents in chemical industry park, the sequence of "risk perception - risk perspective - risk response - risk communication - risk perception" was used to form causality feedback loops based on the theory and methods of system dynamics. Comparing and analyzing the simulation results, qualitative relationships among state variables of risk perception, risk perspective, risk communication and risk response are obtained. The results show that the diversification of psychological activities can be reflected by the simulated data and images roughly, which has practical significance to strengthen joint safety management.

Keywords: risk perception; system dynamics model; enterprise decision-maker; chemical incident

\section{Introduction}

In recent years, China has been the second largest economy in the world, with the chemical industry accounting for a large proportion of the economy. The growth is being fueled by construction of chemical industrial parks all over the country. It is reported that the number of chemical industrial parks and the parks with independent chemical sectors was more than 1,200
\end{abstract}


by the end of 2011 [1]. Due to the concentration of dangerous substances and energy in chemical industrial parks [2], it is bound to form unique risk characteristics, including several aspects listed below[3-7].

1) Many different kinds of major hazards are relatively concentrated

2) Prone to a chain reaction (domino effect)

3) Huge losses of lives and property caused by incidents

4) Destructive effect on the surrounding environment

5) Challenges with regard to emergency response during incidents

6) Huge negative social impact caused by incidents

Chemical plants provide immense benefit to the society; however, incidents such as the 1984 Bhopal incident remind people about the potential risks from the plants and chemical parks [8]. Past chemical incidents have caused heavy casualties and some would argue a huge psychological impact on the society. Many past chemical incidents have made people feel panicky for potential future incidents. Thus, it is important to understand how different people form risk concepts, and construct risk perceptions, which can promote effective risk communication in chemical risk management. Although many scholars have done some research [9-13] on these issues, there are still a number of challenges in understanding the complex mental processes. Due to the different risk concepts and risk perspectives of different stakeholders(i.e., lay people, experts, decision makers), risk communication is not always successful in accomplishing its objectives due to many barriers caused in communication among different people [14], sometimes even causing public anger and conflicts, such as the most famous para-xylene (PX) events in China.

Risk perception means the individual feeling and understanding a variety of objective risks which exist in the outside world. It emphasizes the influence of experience from the individual intuitive judgment and subjective feeling on cognition to analyze, control and manage the risks. Li Naiwen has studied the simulation of individual risk perception factors on high-risk miners, simulated dynamic evolution process of miners' risk perception level and effect of each factor on the risk perception [15].

System dynamics is a discipline which focuses on the research and analysis of the information feedback system. And it is also an integrated cross-disciplinary field which can recognize and solve system problems. According to the characteristic that internal system constituent elements reinforce each other, the root of problems could be found out from the internal structure of the system. Shahbaz Khan studied the complex behavior of hydrological systems by using the theory and method of system dynamics, it explains the complex, non-linear and two-way biophysical processes of each factors in feedback loop system [16].

The aim of this paper is to research the change of risk perception simulation of the enterprise decision-makers during chemical incidents. The conflicts of risk perception are analyzed in section 2 and the risk perspectives of enterprise decision-makers are presented in section 3. In section 4 the quantitative system simulation models are establish, and simulation results are analyzed to illustrate the rationality. In section 5 Sensitivity analysis of the influencing variables for risk perception are carried out, which can support further risk 
communication and management.

\section{Conflicts of risk perceptions}

\section{1 risk concepts}

How to define risk is the basic problem of understanding, assessing and managing the unforeseen and potential risks. However, there are numerous definitions of the risk concept in literature, the main definitions are listed in the Table 1[17].

\section{Table 1 Concepts of risk}

\begin{tabular}{lcc}
\hline & Risk concept & Abbreviations \\
\hline 1 & event or consequence & $\mathrm{R}=\mathrm{C}$ \\
2 & expected value (loss) & $\mathrm{R}=\mathrm{E}$ \\
3 & uncertainty & $\mathrm{R}=\mathrm{U}$ \\
4 & objective uncertainty & $\mathrm{R}=\mathrm{OU}$ \\
5 & $\mathrm{R}=\mathrm{ISO}$ \\
6 & $\mathrm{R}=\mathrm{P}$ \\
7 & probability of an (undesirable) event & $\mathrm{R}=\mathrm{PO}$ \\
8 & potential/possibility of a loss & $\mathrm{R}=\mathrm{C} \& \mathrm{U}$ \\
9 & probability and scenarios/consequences/severity of & $\mathrm{R}=\mathrm{P} \& \mathrm{C}$ \\
& & \\
\hline
\end{tabular}

From Table 1, the risk concepts can be divided into two levels. Firstly, risk is just directly described as consequences (event, loss, uncertainty and effect), and this level's risk would be called one-dimensional risk (Fig 1a). Secondly, risk is not just consequence, but also involves the possibility and probability, this level's risk would be called the two-dimensional risk (Fig 1b). Further, the development of risk concept from past to now, it is already not only viewed as one-dimensional and two-dimensional risk, but has also extended to three-dimensional and multi-dimensional risk which involves the risk perception and risk acceptability (Fig 1c).

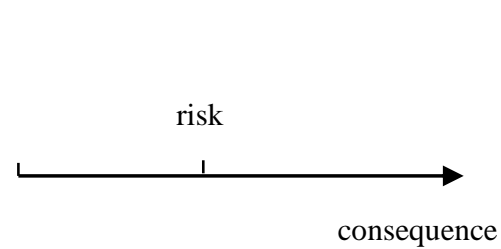

(a) one-dimensional risk

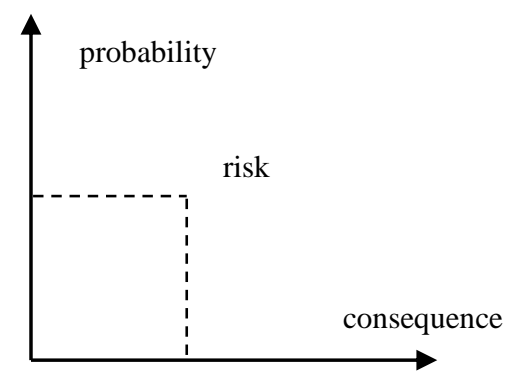

(b) two-dimensional risk 


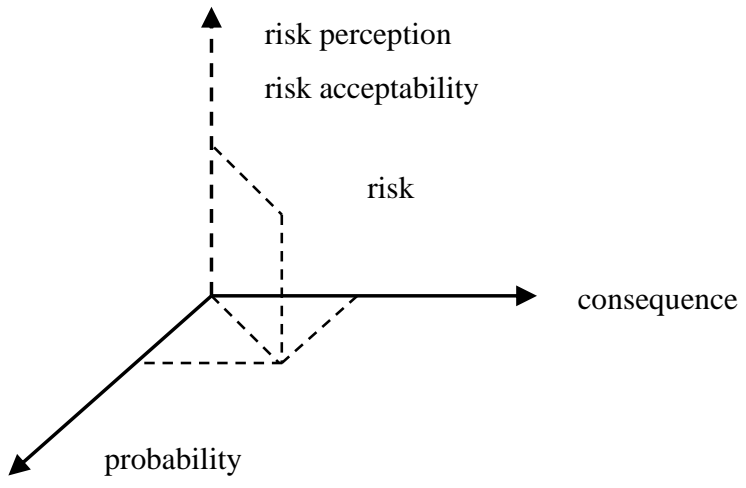

(c) Description of three-dimensional and multi-dimensional risk

Fig.1. Description of (a) one-dimensional (b) two-dimensional risk (c) three-dimensional and multi-dimensional risk

\section{2 framework of risk communication}

For different groups of people, risk perception is a subjective process based on risk concepts discussed above. When they feel the risk of chemical hazards, they will communicate with each other, even evolve into violent resistance as demonstrated by the PX events in Xiamen. Thus, for balancing the benefit and risk and reducing the unnecessary fear of people, the barriers caused by risk communication should be studied in depth and the mechanisms of barrier formation should be clearly understood. Based on that understanding, effective solutions should be put in place among the lay people, expert and the decision-maker. Literature provides us with an example of a mental process established for construction workers [18]. And it forms a feedback loop for studying the safety attitudes and behaviors (i.e., risk perception $\rightarrow$ safety attitude $\rightarrow$ intention $\rightarrow$ behavior $\rightarrow$ outcome $\rightarrow$ risk perception). A similar mental process for the chemical risk communication system was established, as shown in Fig. 2.

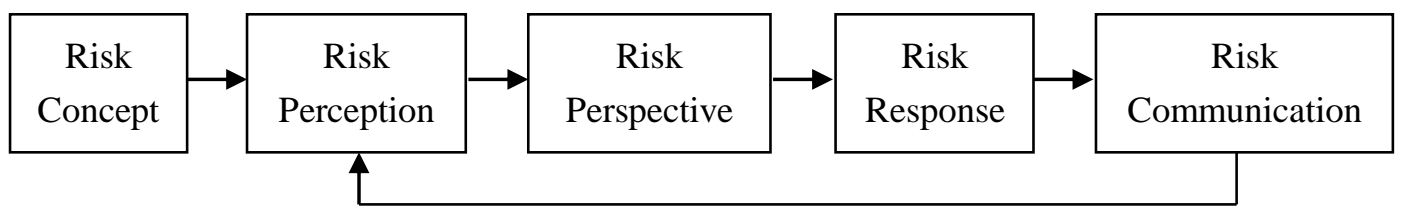

Fig.2 The mental process of risk communication

\section{Risk perspectives of enterprise decision-makers}

When facing chemical incident risks, different people may have different risk perspectives due to different influencing factors including environment, culture, religion, education, willingness of the individual, personal experience and chemical incident information. Furthermore, risk perspectives will make decision-makers take different actions while facing risks, even cause barriers in risk communication.

As Aven [17] summarized that most of the risk perspectives contain three components: 1) the 
initiating events or hazards, 2) the consequences of these events or hazards if they should occur, 3 ) the probabilities of 1) and 2). This summary is in accordance with the risk concepts in one-dimensional and two-dimensional concept. But when communicating risk, risk perception and risk acceptability are the integral parts. According to reference [14], the reality of China and the scenarios of risk communication, the risk perspective of decision-maker are summarized in Table2.

Table 2 Risk perspectives of decision-maker

\begin{tabular}{|c|c|c|}
\hline Group & Risk perspective & Explanation/Example \\
\hline Decision & $\begin{array}{l}\text { 1.A chaotic understanding } \\
\text { of risk }\end{array}$ & No definite views \\
\hline $\begin{array}{l}\text { maker(including } \\
\text { government and }\end{array}$ & $\begin{array}{l}\text { 2.Based on probability of } \\
\text { accidents }\end{array}$ & Consider the possibility of accident \\
\hline enterprise decision & 3. Seeking truth from facts & Scientific evaluation, people-oriented \\
\hline makers in China) & $\begin{array}{l}\text { 4. Based on his/her own } \\
\text { merits }\end{array}$ & Consider merits and career \\
\hline
\end{tabular}

\section{Risk perception causality of enterprise decision-maker}

\subsection{Influence factors analysis}

When the unexpected incident occurs, the enterprise decision-maker would be the first group to receive real-time information. Usually the initial information is a combination of the risk loss information made up of loss value of enterprise property and human casualties. In the process of receiving incident information, risk perspective is slowly formed, also it is influenced by acceptable risk information and incident experience. Effective risk communication is the best way for the enterprise decision-maker to re-establish credibility and gain the support of other stakeholders. So that the risk response (strategy) could be established to reduce the degree of risk perception for enterprise decision-maker, and the risk response (strategy) is intricately tied to the risk scenarios, probability level, strategy styles, risk appetite utility and achievement motivation level. This constitutes the negative feedback loop A.

However, there is also a negative feedback loop B, its working mechanism is familiar with the mechanism of lay people.

\subsection{SD causality of risk perception}

Through the analysis of influence factors of risk perception, causality diagram of risk perception for enterprise decision-maker in chemical industry park could be established. 


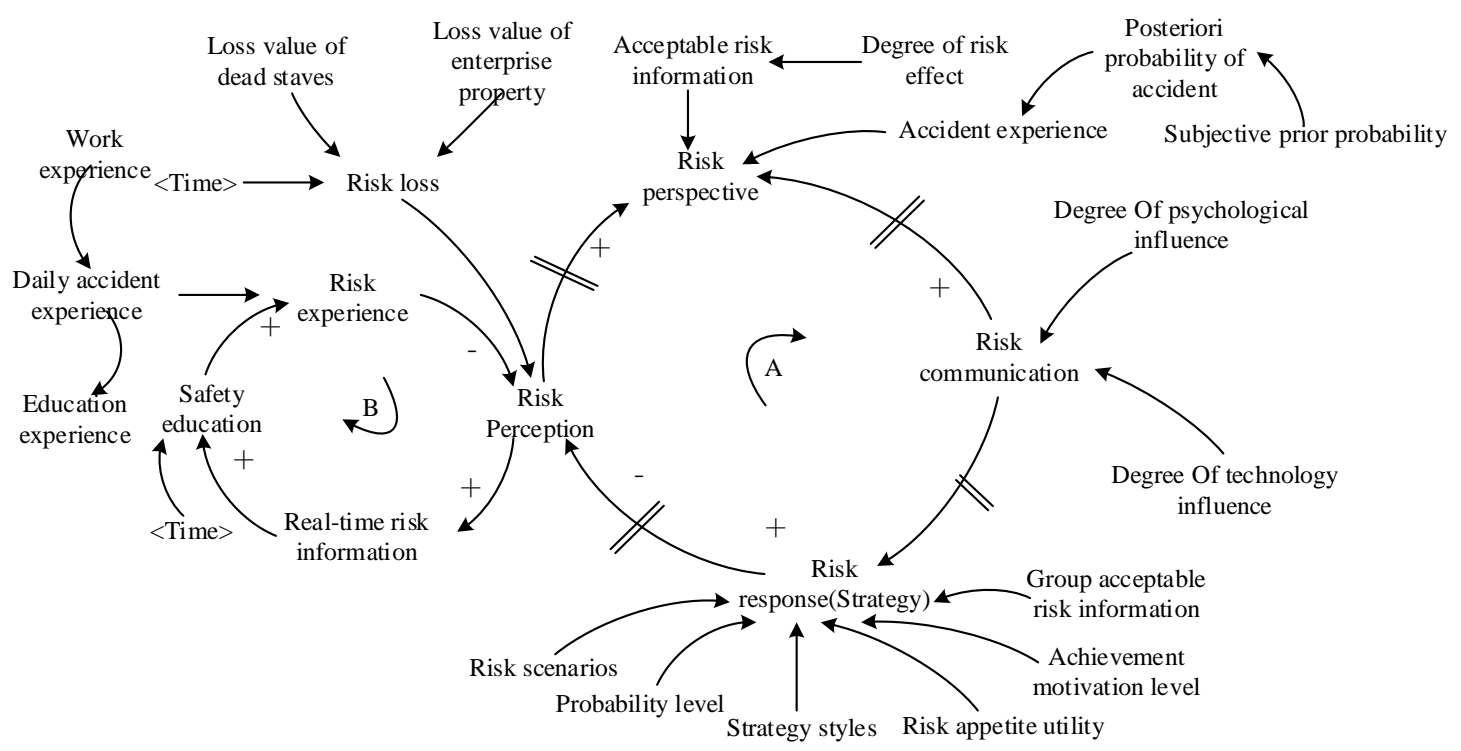

Fig.3 SD causality of enterprise decision-maker risk perception in chemical industry park

In Fig.3, the mental process also is the primary feedback loop (LOOP A) of the SD model and another feedback loop (LOOP B) is involved in it.

Loop A: Risk perception $\rightarrow$ Risk perspective $\rightarrow$ Risk communication $\rightarrow$ Risk response(strategy) $\rightarrow$ Risk perception.

Loop B: Risk perception $\rightarrow$ Real-time risk information $\rightarrow$ Safety education $\rightarrow$ Risk experience $\rightarrow$ Risk perception.

Loop A is mainly used for explaining the role caused by risk response, and Loop B caused by self-adjustment for putting forward effective advices to reduce the degree of risk perception.

Among these two feedback loops, the incident experience is constituted by risk experience and real-time risk information as well as the posterior probability of incident. While the risk experience refers to the personal risk experience that is transformed by the risk information that the enterprise decision-maker is usually exposed to in the process of management.

\subsection{System dynamics model construction}

Based on the principle and method of system dynamics, in combination with two feedback loops (A and B), the SD model of risk perception for enterprise decision-maker could be formed as shown in Fig 4. 


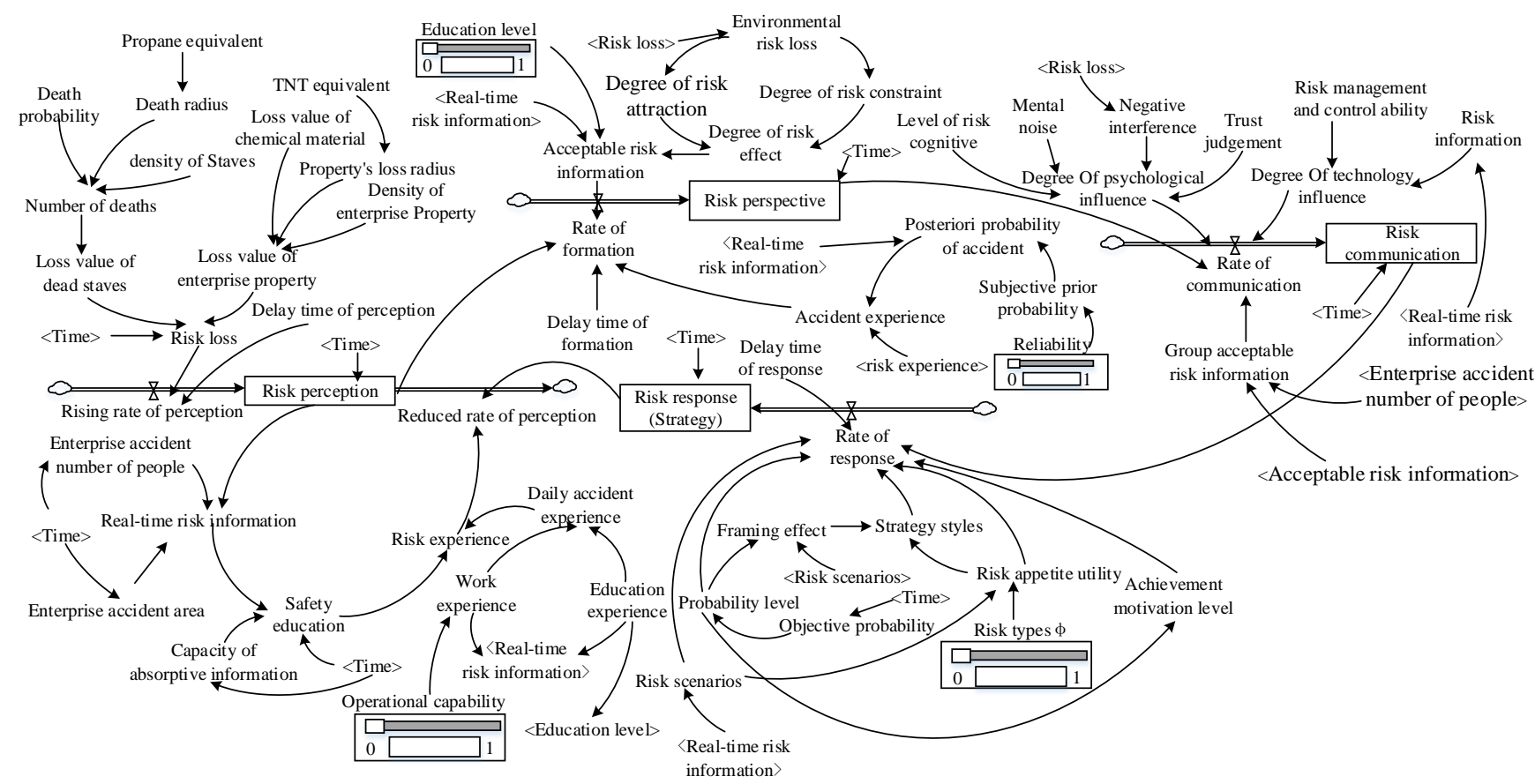

Fig.4 SD model of enterprise decision-maker risk perception in chemical industry park

\subsection{Cause trees}

As show in Fig.4, the SD model was formed with the cause trees of risk perception, risk perspective and risk response (strategy).

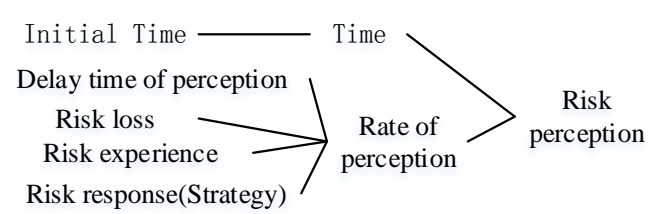

(a) SD causal tree of risk perception

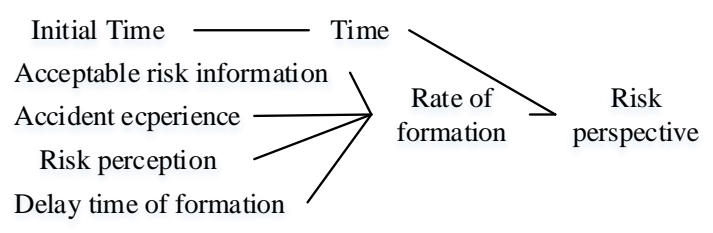

(b) SD causal tree of risk perspective

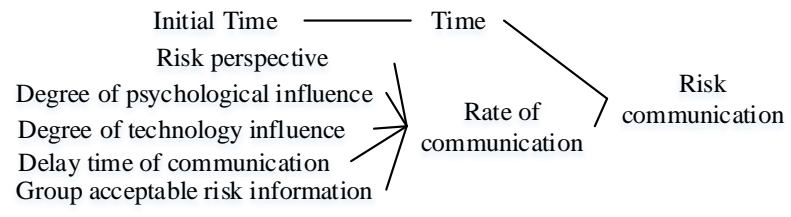




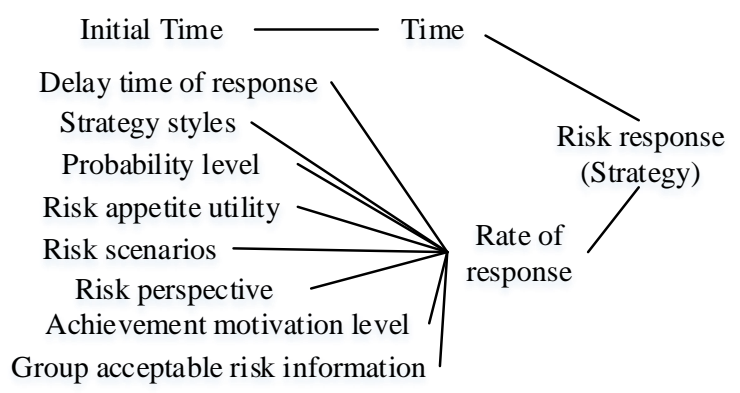

(c) SD causal tree of risk communication (d) SD causal tree of risk response (strategy)

Fig. 5. SD causal trees for (a) risk perception (b) risk perspective (c) risk communication (d) risk response.

\subsection{Variables Summary of SD}

From Fig.5, the multiple state variables involved in developing the system model such as the auxiliary variables, rate variables, implicit variables and constants are summarized in Table 3.

Table 3 Variables summary of risk perception system model

\begin{tabular}{|c|c|c|}
\hline \multicolumn{2}{|c|}{ Variable type } & Variable name \\
\hline \multicolumn{2}{|c|}{ State variables } & $\begin{array}{l}\text { Risk perception } \mathbf{A} \backslash \text { Risk perspective } \mathbf{B} \backslash \text { Risk communication } \mathbf{C} \backslash \text { Risk } \\
\text { response (Strategy) D. }\end{array}$ \\
\hline & $\begin{array}{c}\text { Level-one } \\
\text { auxiliary } \\
\text { variables }\end{array}$ & 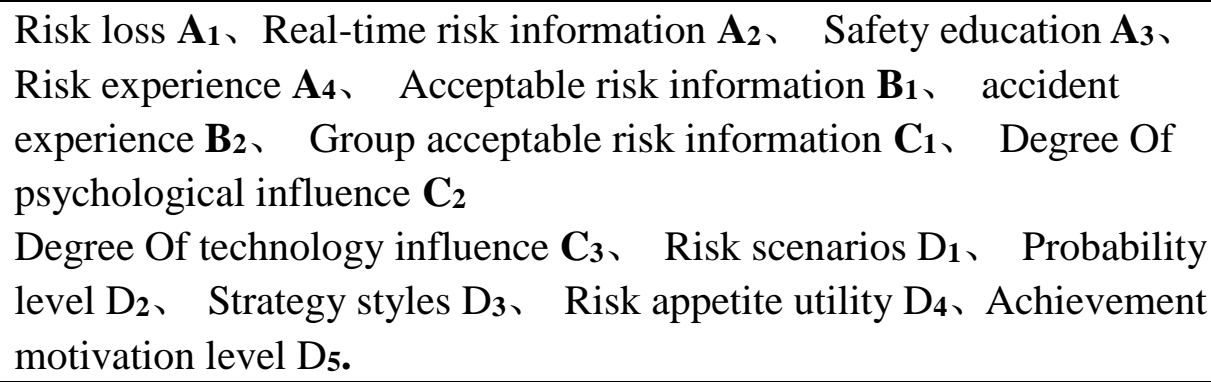 \\
\hline $\begin{array}{l}\text { Auxiliary } \\
\text { variables }\end{array}$ & $\begin{array}{r}\text { Level-two } \\
\text { auxiliary } \\
\text { variables }\end{array}$ & 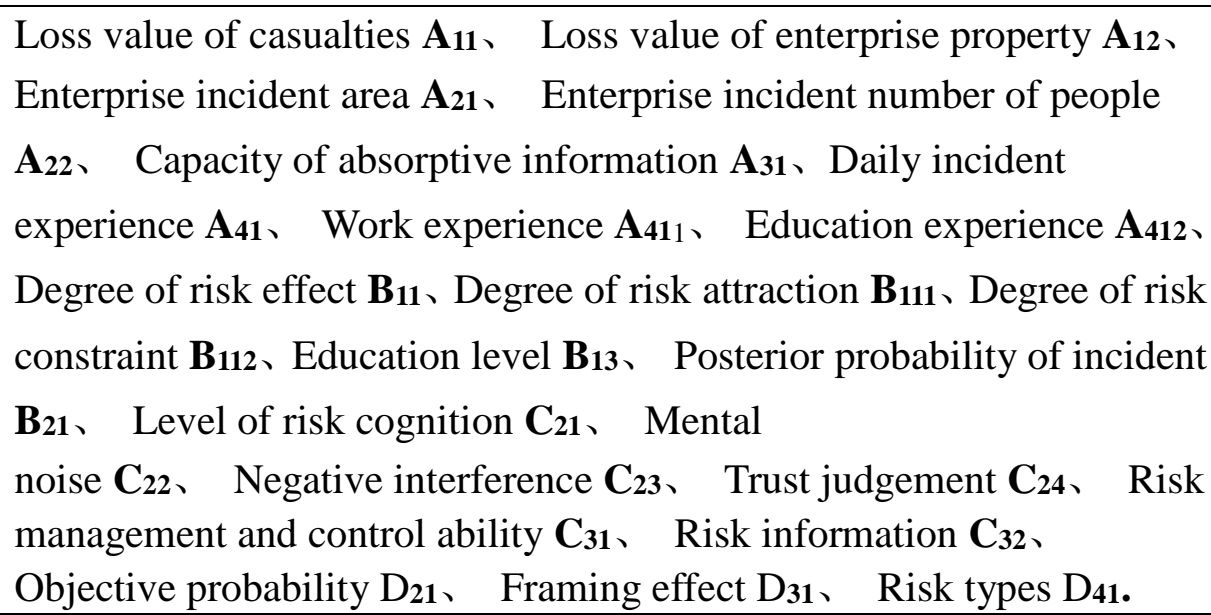 \\
\hline
\end{tabular}




\begin{tabular}{cl}
\hline \multirow{2}{*}{ Rate variables } & $\begin{array}{l}\text { Rising rate of perception } \mathbf{V}_{11} 、 \text { Reduced rate of perception } \mathbf{V}_{12} 、 \quad \text { Rate } \\
\text { of formation } \mathbf{V}_{\mathbf{2}} 、 \text { Rate of communication } \mathbf{V}_{\mathbf{3}} 、 \text { Rate of response } \mathbf{V}_{\mathbf{4}} .\end{array}$ \\
\hline \multirow{2}{*}{ Implicit variables } & $\begin{array}{l}<\text { Time }><\text { Real-time risk information }>\text { <Risk experience }> \\
\text { <Enterprise incident number of people>. }\end{array}$ \\
\hline \multirow{2}{*}{ Constants } & $\begin{array}{l}\text { Operational capability } \mathbf{S}_{\mathbf{1}} 、 \text { Education level } \mathbf{S}_{\mathbf{2}} 、 \text { Reliability } \mathbf{S}_{\mathbf{3}} 、 \text { Risk } \\
\text { types } \mathbf{S}_{\mathbf{4}} \text {. }\end{array}$ \\
\hline
\end{tabular}

\subsection{Construction of SD simulation equation}

Combining with the system dynamics model and the rule among each parameter, mathematical logic relationship can be set up. Many functions are included such as the cumulative distribution function, linear function, exponential function, power function, random function, integral function, if then else computer language and ramp function; so that the system dynamics can be simulated effectively, reasonably and feasibly. Part of the functionality among system variables is shown in table 4 .

Table 4 Major variables relationships and relevant comments

\begin{tabular}{|c|c|c|c|}
\hline Num & Variable & Relationship & Annotation \\
\hline 1 & A & $\sum\left[\left(\mathrm{V}_{11}-\mathrm{V}_{12}\right)^{*}\right.$ Time $\left.)\right]$ & Accumulation of risk perception. \\
\hline 2 & $\mathrm{~B}$ & $\sum\left(\mathrm{V}_{2} *\right.$ Time $)$ & Accumulation of risk perspective. \\
\hline 3 & $\mathrm{C}$ & $\sum\left(\mathrm{V}_{3} *\right.$ Time $)$ & Accumulation of risk communication. \\
\hline 4 & $\mathrm{D}$ & $\sum\left(\mathrm{V}_{4} *\right.$ Time $)$ & Accumulation of risk response \\
\hline 5 & $\mathrm{~A}_{1}$ & $\left(\mathrm{~A}_{11}+\mathrm{A}_{12}\right) *$ Time & $\begin{array}{c}\text { Risk loss }=(\text { Loss value of dead staves }+ \text { Loss } \\
\text { value of enterprise property)*Time[19]. }\end{array}$ \\
\hline 6 & $\mathrm{~A}_{2}$ & $10000 * \mathrm{~A}_{21}+5000 * \mathrm{~A}_{22}$ & $\begin{array}{l}\text { Custom: assuming that loss of per enterprise } \\
\text { incident area is } 10000 \text { yuan, per incident } \\
\text { number of people is } 10000 \text { yuan. }\end{array}$ \\
\hline 7 & $\mathrm{~A}_{3}$ & $\begin{array}{c}\text { IF THEN } \\
\left.\text { ELSE(Time }<=6, \mathrm{~A}_{2}, \mathrm{~A}_{2} * \mathrm{~A}_{31}\right)\end{array}$ & $\begin{array}{l}\text { Custom: the original } 6 \text { hours is used to Collect } \\
\text { and sort out the risk information, then meet the } \\
\text { Law of the Ebbinghaus forgetting curve[20]. }\end{array}$ \\
\hline 8 & $\mathrm{~A}_{4}$ & $\mathrm{~A}_{41}+\mathrm{RAMP}\left(\mathrm{A}_{3}, 1,100\right)$ & $\begin{array}{c}\text { Risk experience }=\text { Daily incident experience }+ \\
\text { real-time experience }\end{array}$ \\
\hline 9 & $\mathrm{~A}_{41}$ & $\begin{array}{c}\operatorname{RAMP}\left(\mathrm{A}_{411}, 1,100\right)+\mathrm{RAMP}( \\
\left.\mathrm{A}_{412}, 1,100\right) \\
\end{array}$ & $\begin{array}{c}\text { Daily incident experience }=\text { education } \\
\text { experience }+ \text { work experience }\end{array}$ \\
\hline 10 & $\mathrm{~B}_{1}$ & $\mathrm{~S}_{2} * \mathrm{~A}_{2} * \mathrm{~B}_{111}$ & $\begin{array}{c}\text { While }-1<\text { DRE }<0, \quad \text { risk attraction is the } \\
\text { mainstream, acceptable risk area }\end{array}$ \\
\hline 11 & $\mathrm{~B}_{11}$ & $\left(\mathrm{~B}_{112}-\mathrm{B}_{111}\right) / \mathrm{B}_{112}$ & $\begin{array}{c}\text { Degree of risk effect }=(\text { degree of risk } \\
\text { constraint - degree of risk attraction }) / \text { degree of } \\
\text { risk constraint. }\end{array}$ \\
\hline 12 & $\mathrm{C}_{1}$ & $\mathrm{~A}_{22} * \mathrm{~B}_{1}$ & $\begin{array}{l}\text { Group acceptable risk information }= \\
\text { acceptable risk information * enterprise }\end{array}$ \\
\hline
\end{tabular}




\begin{tabular}{|c|c|c|c|}
\hline & & & incident number of people \\
\hline 13 & $\mathrm{C}_{2}$ & $\begin{array}{c}\left(0.2 * \mathrm{C}_{21}+0.167 * \mathrm{C}_{22}\right) * \mathrm{C}_{23} * \\
\mathrm{C}_{24}\end{array}$ & Degree of psychological influence \\
\hline 14 & $\mathrm{C}_{3}$ & $\mathrm{C}_{31} * \mathrm{C}_{32}$ & $\begin{array}{c}\text { Degree of technology influence }=\text { Effects of } \\
\text { information }\end{array}$ \\
\hline 15 & $\mathrm{D}_{1}$ & $\mathrm{~A}_{2}$ & $\begin{array}{c}\text { Risk scenarios can be presented by real-time } \\
\text { risk information }\end{array}$ \\
\hline 16 & $\mathrm{D}_{2}$ & $\begin{array}{c}\text { IF THEN ELSE } \\
\left(\mathrm{D}_{21}=0,0,2^{\wedge} \mathrm{D}_{21}-0.97\right)\end{array}$ & $\begin{array}{l}\text { Refer to the hypothetical weighting function of } \\
\text { Kahneman and Tversky[21]. }\end{array}$ \\
\hline 17 & $\mathrm{D}_{3}$ & $\mathrm{D}_{31} * \mathrm{D}_{4}$ & $\begin{array}{c}\text { Strategy styles essentially refer to decision } \\
\text { makers' information collection and integration } \\
\text { tendency [22]. }\end{array}$ \\
\hline 18 & $\mathrm{D}_{4}$ & $\left(1-\mathrm{S}_{4} \wedge \mathrm{D}_{1}\right) /\left(1-\mathrm{S}_{4}\right)$ & $\begin{array}{l}\text { The functional expressions of utility measured } \\
\text { as constant risk preference and parameters } \\
\text { determination[23]. }\end{array}$ \\
\hline 19 & $\mathrm{D}_{5}$ & $\begin{array}{c}\text { IF THEN } \\
\text { ELSE(MAX }\left(\mathrm{D}_{2}, 0\right)<0.66 \\
\text { RANDOM UNIFORM } \\
(0.5,1,0.5), \text { RANDOM } \\
\text { UNIFORM }(0,0.5,0.1))\end{array}$ & $\begin{array}{l}\text { Because people are limited in their ability to } \\
\text { comprehend and evaluate extreme } \\
\text { probabilities, highly unlikely events are either } \\
\text { ignored or overweighted, and the difference } \\
\text { between high probability and certainty is } \\
\text { either neglected or exaggerated }\end{array}$ \\
\hline
\end{tabular}

\subsection{System simulation and result analysis}

4.7.1 System simulation of negative feedback A

Loop A: Risk perception $\rightarrow$ Risk perspective $\rightarrow$ Risk communication $\rightarrow$ Risk response (strategy) $\rightarrow$ Risk perception.

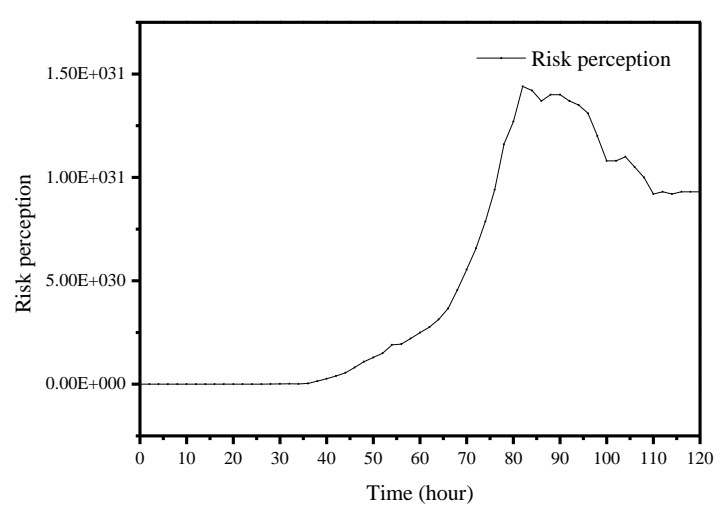

(a) System simulation results of risk perception

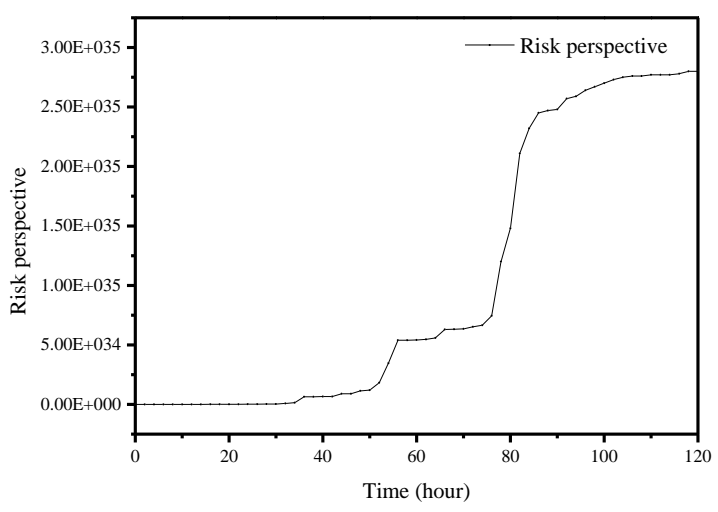

(b) System simulation results of risk perspective 

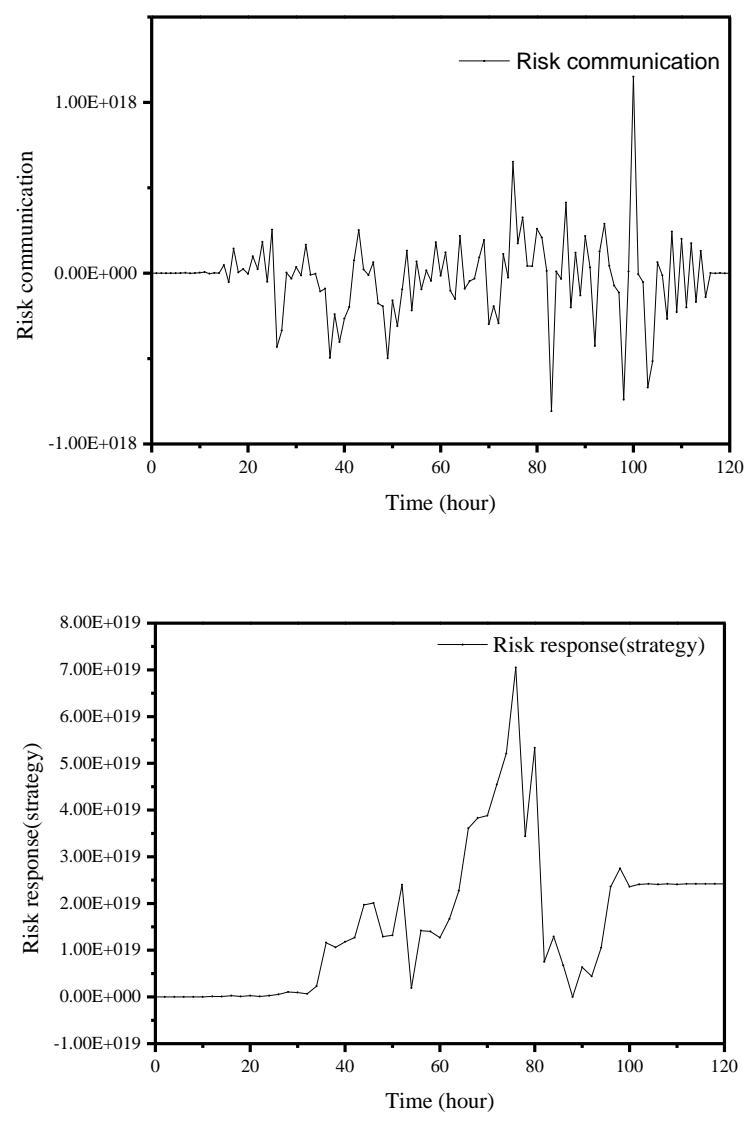

(c) System simulation results of risk communication (d) System simulation results of risk response (strategy)

Fig.6. System simulation results of (a) risk perception (b) risk perspective (c) risk communication $(\mathrm{d})$ risk response (strategy)

(1). Explanation of system simulation results for risk perception

The simulation results of risk perception in fig.6(a) conforms to the actual changes in our life, it also can be broken down into three stages: the initial stage, middle stage and final stage. In the initial stage, enterprise decision-maker would collect, sort and analyze information of site of incident through various channels, at the same time the degree of risk perception beginning to change slowly, despite slow growth, but the overall volatility is still relatively small and the change in simulation results image is not obvious. In the middle stage, with the continuous development of the incident, the degree of risk perception grows rapidly, and the momentum of its growth would slow down eventually. At the end of the middle stage, the degree of risk perception could reach a peak value and no longer grow. In the final stage, due to the influence on the effect of negative loop $\mathrm{A}$ and $\mathrm{B}$, the degree of risk perception will drop slowly again, without rules, until tends to a stable range.

(2). Explanation of system simulation results for risk perspective 
The change of the risk perspective in fig.6(b) is determined by risk perception, personal acceptable risk information and incident experience, and its evolution law is similar to the change of risk perception. Under the influence of risk perception, volatility of risk perspective changes modestly. As time goes on, the degree of risk perspective keeps growing. Nevertheless the rate of formation would be subject to the influence of incident experience and personal acceptable risk information, so it would decline until tends to zero. At this time, the degree of risk perspective would stay in a stable state.

(3). Explanation of system simulation results for risk communication

Risk communication in fig.6(c) is the best way for enterprise decision-maker to make a final decision, reasonably, importantly and without a doubt. Effective incident emergency rescue and reduced social panic could be worked by great communication and interpersonal skills. The curve of simulation results explains the change of risk communication effectively, and it shows a regular risk communication fluctuations: small fluctuations-rapid fluctuations-sharp fluctuations-slow fluctuations, embodying the frequency and the utility of risk communication that the enterprise decision-maker must face.

(4). Explanation of system simulation results for risk response (strategy)

Risk response (strategy) in fig.6(d) includes the emergency disposal measures and response mechanisms that are used for dealing with unexpected incidents. Risk response along with the development of the whole process of the incident increases gradually. The strategic and timely increase or risk response mitigates the severity of the incident and ultimately control the incident effectively. As the situation gets better, the risk response measures are reduced until the incident is under full control.

\subsubsection{System simulation of negative feedback B}

Loop B: Risk perception $\rightarrow$ Real-time risk information $\rightarrow$ Safety education $\rightarrow$ Risk experience $\rightarrow$ Risk perception.

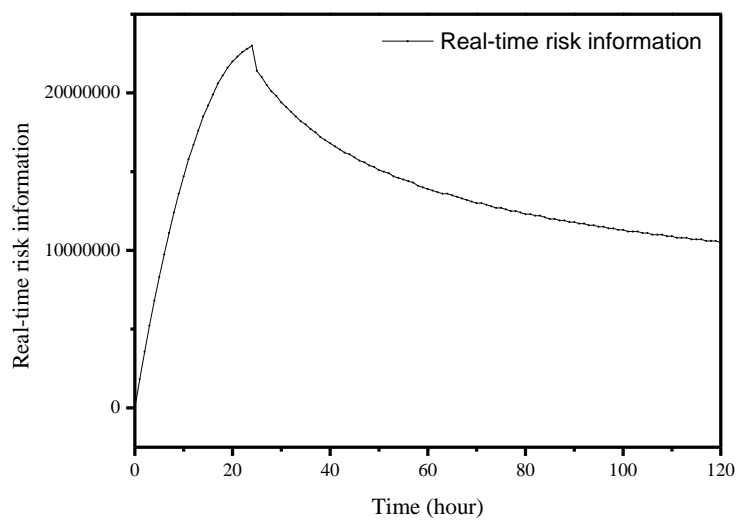




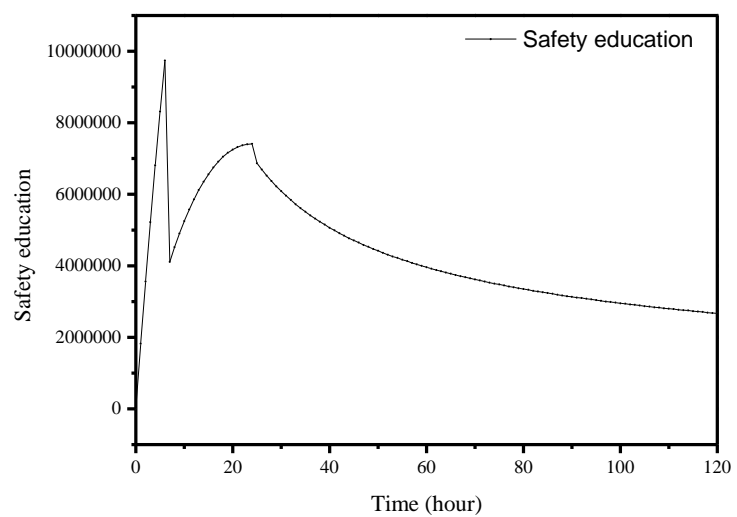

$\begin{array}{ll}\text { (a) System simulation results of real-time risk information } & \text { (b) System simulation results of }\end{array}$ safety education

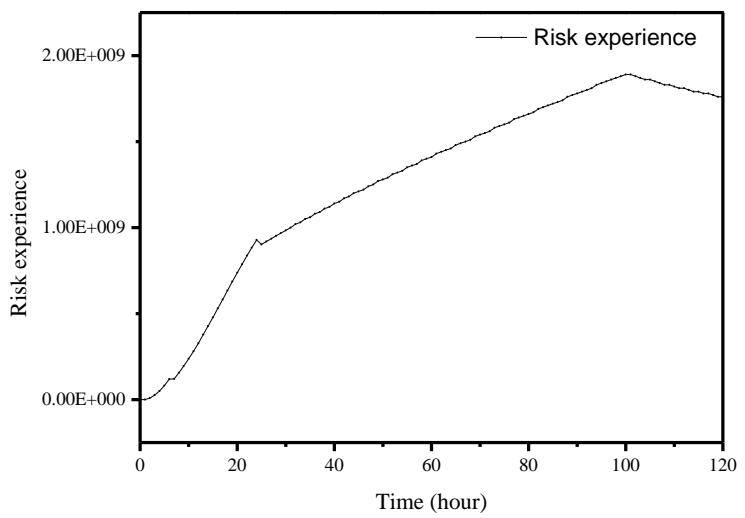

(c) System simulation results of risk experience

Fig.7. System simulation results of (a) real-time risk information (b) safety education (c) risk experience

(1). Explanation of system simulation results for real-time risk information

Real-time risk information is made up of enterprise incident area and enterprise incident number of people. Assuming that economic loss per enterprise incident area is 10000 yuan, and per incident number of people is 10000 yuan, so the simulation result could be shown in fig.7(a), performing the change in each time period of real-time risk loss. As the incident unfolds, the loss to the enterprise would rise rapidly, while the risk response effects on risk perception, rate of real-time risk information would slow and the quantum would increase slowly, or even be reduced. The reason of the results could not be shown explicitly in fig.7(a) is that the simulation time was limited to 120 hours. However the simulation results in fig.7(a) present the change of real-time risk information.

(2). Explanation of system simulation results for safety education 
The change of safety education can be divided into two stages. In the first stage, the enterprise decision-maker was collecting and assimilating information about incident, so the knowledge that the enterprise decision-maker mastered was the collected incident information, that is the real-time risk information, also it was a function of the ability to absorb information until the capacity of information was saturated. In the second stage, mastery of the degree of incident information follows the $\mathrm{H}$. Ebbinghaus memory curve evolution law, finally tends to a stable value.

(3). Explanation of system simulation results for risk experience

Risk experience was in conformity with the evolution trend of rapid - slow - slight- stable. Risk experience consists of daily incident experience and the experience originates in the incident scene, the daily incident experience derived from work experience and education experience. Also the experience originates in the incident scene transformed from the real-time safety education. Experience was accumulated in the daily and actual scene.

\section{Sensitivity analysis of the influencing variables for risk perception}

\subsection{Risk perception（state variable）}

By altering the risk experience value in the sensitivity analysis, the change of risk perception could be explored. The value of risk experience were divided into three kinds: Intact, half, double and the contrast results are shown in Figure.8.

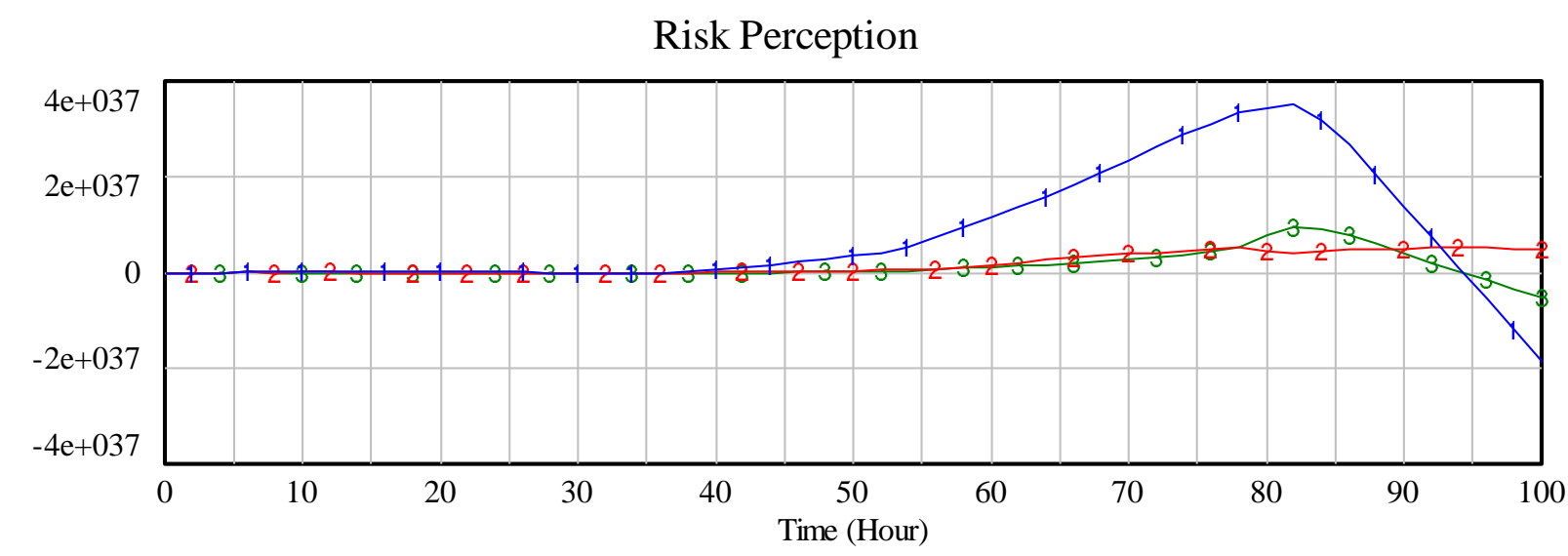

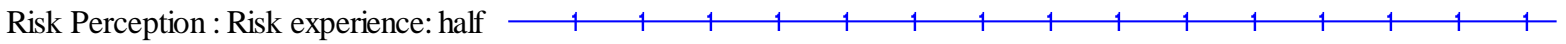
Risk Perception : Risk experience: Double $\begin{array}{lllllllllllllllll}2 & 2 & 2 & 2 & 2 & 2 & 2 & 2 & 2 & 2 & 2 & 2 & 2 & 2 & 2\end{array}$

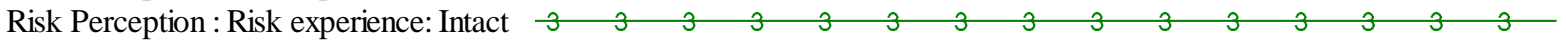

Fig.8. Contrast results of risk perception-risk experience

Contrast results showed that fluctuation level: half $>$ intact $>$ double.

The reason: with the increase of risk experience, reduced rate of perception would rise, so the stock of risk perception would be dropped.

Conclusion: the relationship between risk perception and risk experience is negative. 


\subsection{Risk perspective（state variable）}

By changing the education level and the sensitivity analysis, the change of risk perspective could be explored. The degree of education was divided into four kinds: None, Middle school, High school, University. And the contrast results are shown in Figure 9.

Risk perspective

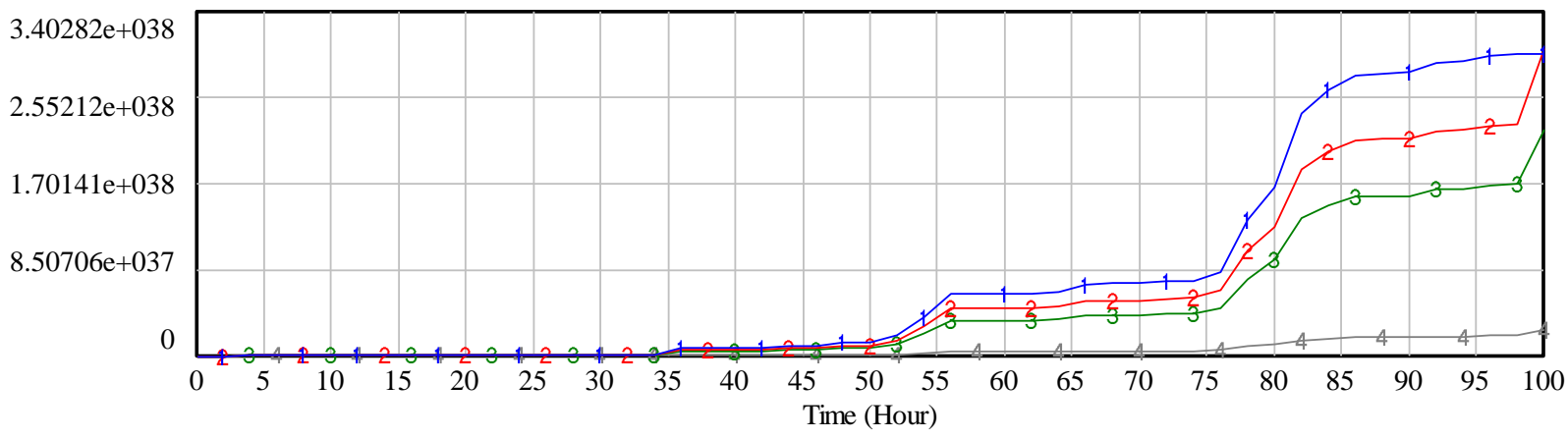

Risk perspective : Education level : University

Risk perspective : Education level : High school

Risk perspective : Education level : Middle school

Risk perspective : Education level : None

Fig.9. Contrast results of risk perspective-education level

Contrast results showed that fluctuation level: University > High school > Middle school > None.

The reason: with the increase of education level, acceptable risk information would be received more and more, so as to the rate of formation, ultimately the formation of risk perspective would be in argument.

Conclusion: the relationship between risk perspective and education level is positive.

\subsection{Risk communication (Auxiliary variable)}

By changing the sensitivity analysis of level of risk cognitive and mental noise, the change of risk communication could be explored. The contrast results are shown in Figure 17(a) and (b).

(1) Level of risk cognitive (Positive effect)

The degree of risk cognitive were divided into five levels: Low, Slightly lower, Medium, Slightly higher and High. Assignment: 20-Low, 40-Slightly lower, 60-Medium, 80-Slightly higher, 100-High. And the contrast results are shown in figure10(a) 
Risk communication
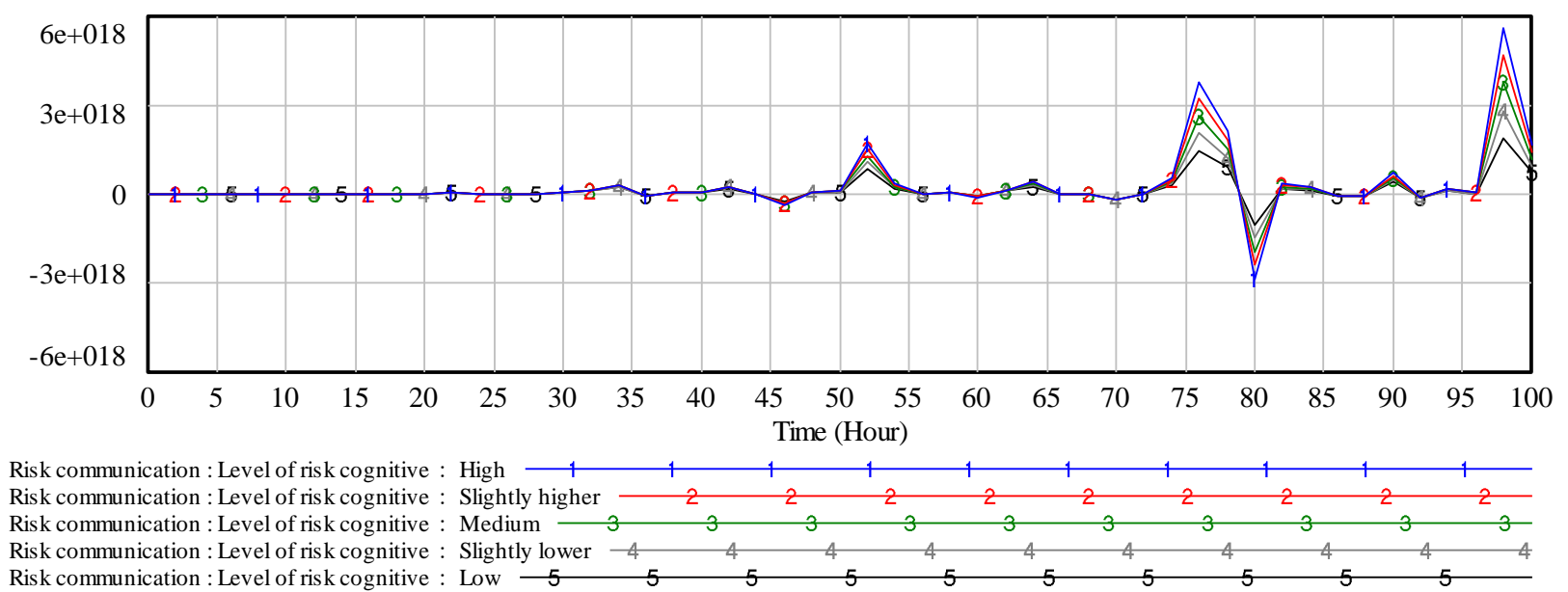

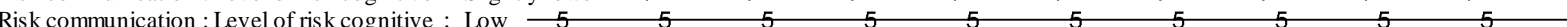

Fig.10(a). Contrast results of risk communication-risk cognitive

Contrast results showed that fluctuation level: High > Slightly higher >Medium >Slightly lower > Low.

The reason: with the increase of risk cognitive, rate of communication would rise, so the stock of risk communication would be increased.

Conclusion: the relationship between risk communication and level of risk cognitive is positive.

(2) Mental noise (Negative role)

The level of mental noise was divided into six levels: None(<30db), dispensable(30 40db), slightly(40 50db), worry(50 70db), afraid(70 90db) and fear(>90db). Assignment: 20-None, 35-dispensable, 45-slightly, 60-worry, 80-fraid.and 100-fear. The contrast results are shown in Figure 10(b).

Risk communication

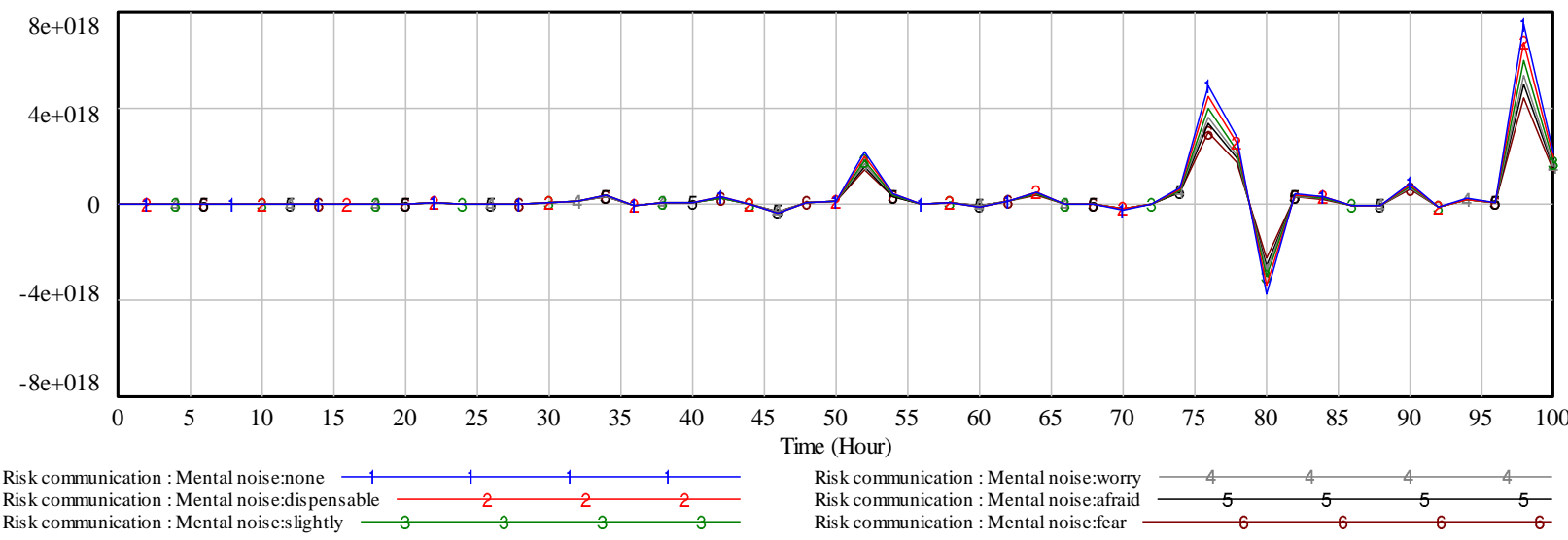

Fig.10(b). Contrast results of risk communication-mental noise

Contrast results showed that fluctuation level: None $>$ dispensable >Slightly > Worry $>$ Afraid $>$ Fear.

The reason: with the increase of mental noise, rate of communication would be dropped, so 
the stock of risk communication would be reduced

Conclusion: the relationship between risk communication and mental noise is negative.

\subsection{Risk response (strategy)（state variable）}

By changing the sensitivity analysis of risk styles, the change of risk response (strategy) could be explored. The contrast results are shown in Figure 18. Because the risk appetite utility was determined by the risk styles, and the risk styles could be divided into three kinds: Risk aversion, Risk neutral and Risk seeking, and the formula of the risk appetite utility is:

$$
\text { Risk appetiteutility }=\frac{\left(1-\text { Risk types }_{\mathrm{D}}^{\text {Riskscenainos }}\right)}{1-\text { Risk types }_{\mathrm{D}}}
$$

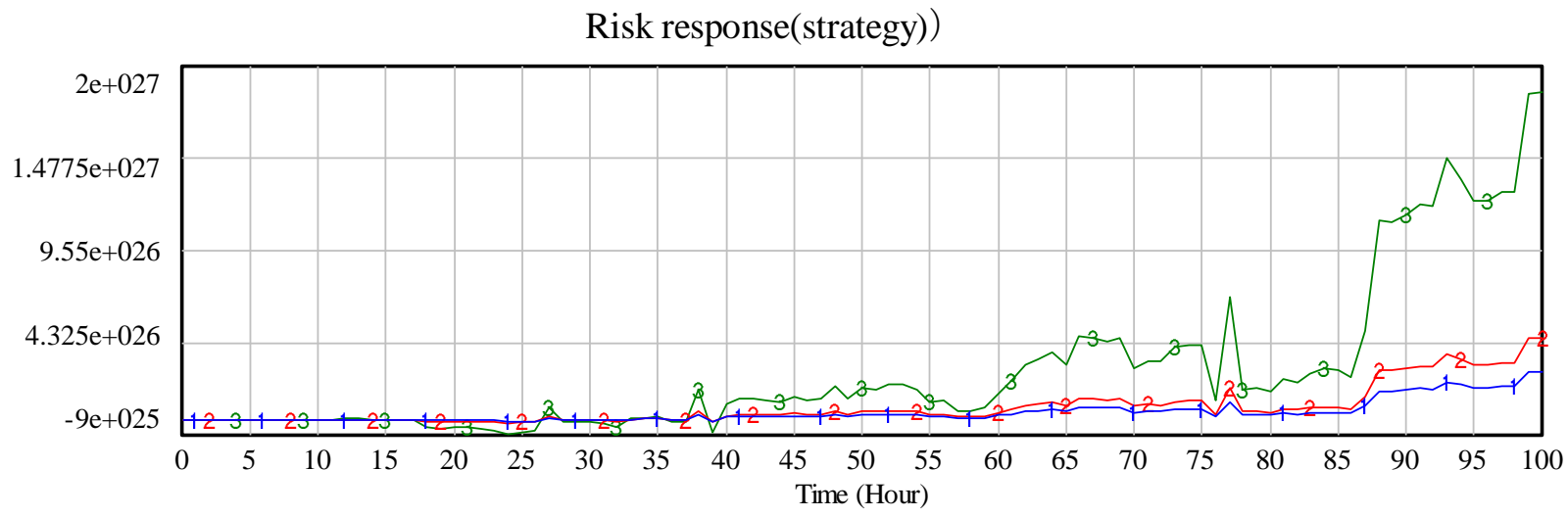

"Risk response(strategy)) " : Risk Neutral: $(p<1$

"Risk response(strategy)) " : Risk Neutral: $\varphi=1$

"Risk response(strategy)) " : Risk Seeking: $\varphi>1$

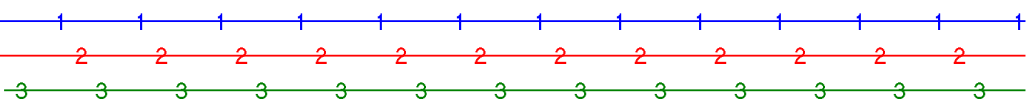

Fig.11. Contrast results of risk communication-risk styles

Contrast results showed that fluctuation level: Risk seeking > risk neutral > risk aversion

Conclusion: the relationship between risk communication and risk styles is positive.

\section{Conclusions and further work}

For the decision-maker of chemical enterprise, this paper takes the "risk perception - risk perspective - risk response - risk communication - risk perception" as the sequence through which risk communication works.

1. When it turns to the simulation of risk perception for enterprise decision-maker, SD causality model was established based on analysis of influencing factors, which contains two main feedback loops.

Loop A: Risk perception $\rightarrow$ Risk perspective $\rightarrow$ Risk communication $\rightarrow$ Risk response (strategy) $\rightarrow$ Risk perception.

Loop B: Risk perception $\rightarrow$ Real-time risk information $\rightarrow$ Safety education $\rightarrow$ Risk experience $\rightarrow$ Risk perception.

The negative feedback loop A is mainly used for explaining the role caused by risk response, and the another negative feedback loop caused by self-adjustment for putting forward effective advices to reduce the degree of risk perception. 
2.After building the SD models for enterprise decision-maker, quantitative equation of variables are defined, the evolving process of risk perception, risk perspective, risk communication and risk response (strategy) have been simulated, and the corresponding results are analyzed.

3. Sensitive analysis of influence variables provides the following conclusions:

- the relationship between risk perception and risk experience is negative.

- the relationship between risk perspective and education level is positive.

- the relationship between risk communication and level of risk cognitive is positive.

- the relationship between risk communication and mental noise is negative.

- the relationship between risk communication and risk styles is positive.

Although the risk perception for enterprise decision-maker have been simulated, as a whole. However, the system also includes the enterprise staff, government policy makers and safety experts who should have been taken into account in the simulation, so that the risk perception for every social group can be evaluated completely.

\section{Acknowledgments}

The authors thank the financial support of the National Natural Science Foundation of China (No. 71001051), the Natural Science Foundation of Jiangsu Province, China (BK 2012824), key project of National Natural Science Foundation of China under Grant (No. 21436006), open subject of Jiangsu Key Laboratory of Hazardous Chemicals Safety and Control (HCSC201304), the Priority Academic Program Development of Jiangsu Higher Education Institutions of China and Jiangsu Government Scholarship for overseas Studies.

\section{References}

[1] SUN Nan-nan, 2011. Construction of emergency evaluating system on incidents occurred in chemical industrial parks based on process management. 2011 International Conference on Engineering and Business Management, China.

[2] Zhang Ming-guang , Jiang Jun-cheng ., 2008. An improved probit method for assessment of domino effect to chemical process equipment caused by overpressure. Journal of Hazardous Materials 158, 280-286.

[3] Genserik Reniers, Paul Amyotte, 2012. Prevention in the chemical and process industries: Future directions. Journal of Loss Prevention in the Process Industries 25, 227-231.

[4] R.M. Darbra, Adriana Palacios, Joaquim Casal., 2010. Domino effect in chemical accidents: Main features and accident sequences. Journal of Hazardous Materials 183, 565-573.

[5] Jianfeng Peng, Yonghui Song, Peng Yuan, Shuhu Xiao, Lu Han, 2013. An novel identification method of the environmental risk sources for surface water pollution accidents in chemical industrial parks. Journal of Environmental sciences 25(7), 1441-1449.

[6] Lei Huang, Wenbo Wan, Fengying Li, Bing Li, Jie Yang, Jun Bi, 2011. A two-scale system to identify environmental risk of chemical industry clusters. Journal of Hazardous Materials 186, 247-255.

[7] Ravi K. Sharma, Bhola R. Gurjar, Akshay V. Singhal, Satish R. Wate, Santosh P. Ghuge, Rajat Agrawal, 2015. Automation of emergency response for petroleum oil storage terminals. 
Safety Science 72, 262-273.

[8] R.Ball ., 2011. Oscillatory thermal instability and the Bhopal disaster . Process Safety and Environmental Protection 89, 317-322.

[9] Terje Aven ., 2010. On how to define, understand and describe risk. Reliability Engineering and System Safety 95, 623-631.

[10] Terje Aven ., 2011. A risk concept applicable for both probabilistic and non-probabilistic perspectives . Safety Science 49, 1080-1086.

[11] Terje Aven, Genserik Reniers ., 2013. How to define and interpret a probability in a risk and safety setting . Safety Science 51, 223-231.

[12] Ortwin Renn., 2004. Perception of Risks . Toxicology Letters 149(1/3), 405-413.

[13] G Grasa, V Navarro, O Rubio,et al.,2002. A comparative study of risk perception in small and large communities where chemical industries are present. Journal of Loss Prevention in the Process Industries 15(6), 525-530.

[14] H Veland, T Aven., 2013. Risk communication in the light of different risk perspectives. Reliability Engineering and System Safety 110, 34-40.

[15] Li Nai-wen, Wang Chun-di, 2015.Simulation of factors affecting individual risk perception of the high-risk position miner . Journal of Safety Science and Technology, (9):184-190.

[16] Khan S, Luo Y, Ahmad A,2009. Analysing complex behaviour of hydrological systems through a system dynamics approach. Environmental Modelling \& Software 24 , (12):1363-1372.

[17] Terje Aven., 2012. The risk concept-historical and recent development trends. Reliability Engineering and System Safety 99, 33-44.

[18] Mingyu Shin, Hyun-soo Lee, Moonseo Park, Myunggi Moon, Sangwon Han., 2014. A system dynamics approach for modeling construction workers' safety attitudes and behaviors. Accident Analysis and Prevention 68, 95-105.

[19] Qian Cheng-jiang, Zhang Ming-guang, Chen Ying-ting,2014. A calculation method of work safety liability insurance premiums for chemical enterprises. China Safety Science Journal24,(5):150-156.

[20] Zhang Lei, 2014. Reaearch recommendation algotithm based on forgetting curve. Anhui University Of Science \& Technology.

[21] Kahneman D, Tversky A, 1979. Prospect Theory: An Analysis of Decision under Risk. Levines Working Paper Archive68, (3):263-91.

[22] Dong Jun-hua,2006. The influential factor and construction of factor model of risk decision-making. Northwest Normal University.

[23] Jiang Shu-yuan, Jiang qing-fang, 2007. The functional expressions of utility measured as constant risk preference and parameters determination [J]. Chinese Journal of Management Science 15, (1):16-20.

[24] Adam S. Markowski, M. Sam Mannan, Agata Kotynia, Dorota Siuta, 2010. "Uncertainty Aspects in Process Safety Analysis, Jounral of Loss Prevention in the Process Industries, 23, (3):446-454. 